\title{
Effects of size and season of disturbance on algal patch recovery in a rocky intertidal community
}

\author{
Jeong Ha Kim*, Robert E. DeWreede \\ Department of Botany, The University of British Columbia, Vancouver, British Columbia, Canada V6T 124
}

\begin{abstract}
Effects of gap size and the season of clearing on algal patch recovery were investigated in a high rocky intertidal shore of British Columbia, Canada, to understand community dynamics in relation to physical disturbance. The community studied contains 3 dominant perennial macroalgae, Mazzaella cornucopiae (= Iridaea cornucopiae, Rhodophyta), Fucus distichus and Pelvetiopsis limitata (Phaeophyta), and some ephemeral algae as well as barnacles and limpets. The experimental design comprised 3 gap sizes of clearing $(5 \times 5 \mathrm{~cm}, 10 \times 10 \mathrm{~cm}$ and $20 \times 20 \mathrm{~cm}$ ) and 4 seasonal clearings (August 1991. October 1991, February 1992, April 1992). The recolonization rate of all algal species was fastest in the medium gaps, followed by the small and large gaps. Thus, medium gaps were filled by a relatively well-mixed combination of all algal species including $M$. cornucopiae (rare in large gaps) and $F$. distichus (low in small gaps). Responses of each alga to the different sizes of clearing were speciesspecific and related to the alga's reproductive characteristics. The results indicate that negative factors (e.g. whiplash, desiccation) were probably responsible for slow colonization in the 2 extreme sizes of gap. Different algal species responded differently to the gaps cleared in different seasons. New substrata created a short time (e.g. 2 mo) before the peak of fucoid recruitment in unmanipulated plots received a greater number of fucoid propagules, and this initial recruitment secured fucoid persistence in the later successional period. On the other hand, for $M$. cornucopiae, which propagates mostly vegetatively, the timing of clearing generally did not influence dominance of this alga in the patches. Barnacle densities during the experimental period were less in small gaps than in medium and large gaps, but limpet abundance was not significantly influenced by clearing size. The kinds of algal species which move in when a gap of a particular size is created in a particular season were predicted for this community using the interaction terms of size and season effects of disturbance.
\end{abstract}

KEY WORDS: Disturbance - Fucus distichus Intertidal Mazzaella cornucopiae Patch recovery Pelvetiopsis limitata. Season (time) $\cdot$ Size

\section{INTRODUCTION}

Disturbance and subsequent patch recovery in the disturbed area are paramount in the understanding of the variability of community structure and dynamics in many habitats. Disturbance is defined here as any discrete event that reduces the amount of living biomass in an area and opens up space for the establishment of new individuals or colonies. In marine benthic habitats, the formation of gaps is of considerable significance to sessile organisms which require open space. Various attributes of a newly created gap (i.e. its

\footnotetext{
•E-mail: jhkim@unixg.ubc.ca
}

size, shape, location and time of creation) can affect subsequent patch colonization and ensuing biological interactions (Sousa 1985). Investigators have extensively studied various aspects of disturbance on succession and community structure in marine habitats including frequency (Connell 1978, Sousa 1979a, b, Miller 1982), size (Osman 1977, Paine \& Levin 1981. Keough 1984, Farrell 1989, Dye 1993, BenedettiCecchi \& Cinelli 1994), intensity (Sousa 1980, see Connell \& Keough 1985 for references), location (Palumbi \& Jackson 1982, Sousa 1984a, Dayton et al. 1992), and time or seasonality (Foster 1975, Hawkins 1981, Turner 1983a, Jara \& Moreno 1984, Breitburg 1985, Kennelly 1987. Dayton et al. 1992, BenedettiCecchi \& Cinelli 1994). 
However, recent studies have provided conflicting results regarding the effect of size of disturbance on the rate of algal recovery in the gaps (see Farrell 1989, Dye 1993, Benedetti-Cecchi \& Cinelli 1994); in this paper we investigate this topic further. Due to the differences in gap sizes used, and the tidal heights where the studies were conducted, it is difficult to compare results of previous studies. The rate of colonization may vary with gap size because the biological environments of gaps may vary with size. Organisms secure space by overgrowing or by spreading vegetatively into open space, or by growing from dispersed propagules. Species with particular life histories or reproductive strategies may colonize some areas but not others. For example, the centers of very large gaps are most likely to be colonized by species producing propagules which travel relatively great distances. Such dispersal capability is less important in smaller gaps, since most recolonizing propagules will be produced by individuals established adjacent to the gap (Davis \& Cantlon 1969, Osman 1977, Sousa 1979b, Begon et al. 1990) On the other hand, Sousa (1985) described that the most obvious influence of patch size derives not from the size of a gap per se but from the manner in which the ratio of gap perimeter to area changes with gap size. For example, smaller gaps have a greater ratio of edge to area than larger gaps. Therefore, the number of propagules received per unit area in smaller gaps is greater than that of larger gaps. Sousa's (1985) argument clearly supports the idea that smaller gaps are colonized more rapidly than larger ones, and that this is particularly true when the distance of dispersal is small.

However, smaller patches may be influenced by factors which negatively influence germination of propagules or post-recruitment survivorship of newly settled individuals and consequently slow the colonization process. These factors may include shading (Reed \& Foster 1984, Kennelly 1989), scouring (Velimirov \& Griffiths 1979, Kennelly 1989) and increased herbivory (Sousa 1984a). In intertidal mussel beds, small clearings harbored higher densities of grazers (e.g. limpets) than did large gaps because small gaps provided a greater ratio of edge to area for limpets which tended to aggregate at the edges (Paine \& Levin 1981, Sousa 1984a, Farrell 1989). Consequently, small patches may have a slow colonization due to increasing herbivory. On the other hand, larger patches may also have negative factors which slow the colonization process. These factors include high desiccation and heat stress (particularly for upper intertidal zones) and extremely limited dispersal distances of component species in the community (Sousa 1984a, Farrell 1989)

Barnacles (e.g. Balanus sp.) were influenced by different sizes of disturbance in some studies. Farrell
(1989) found that barnacles settled faster in large gaps probably due to less deleterious effects imposed by algae. Different responses of barnacles to different sizes of gap may affect patch recovery because barnacles are known to facilitate colonization of some algae by modifying the rock surface (Dungan 1986, Farrell 1991, Kim 1995).

Deterministic views of community succession using 1-dimensional models of disturbance (e.g. size) make it more difficult to predict the patterns of community dynamics than when 2- or 3-dimensional models of disturbance are used (e.g. frequency, seasonality) (Miller 1982, Malanson 1984, Sousa 1985). It is highly unlikely that natural disturbance occurs uniformly (i.e. same size or same intensity). Thus its natural occurrence may involve combinations of factors which can often be correlated (Sousa 1980, Paine \& Levin 1981, Miller 1982, Malanson 1984). For example, Paine \& Levin (1981) reported that the largest clearings in mussel beds were created by winter storm waves and such clearings were less frequent than small clearings produced by waves of lesser magnitude in any season. in this case, iue intêaction of size and season characterizes this disturbance. It is clearly important to determine the key characteristics of disturbances which are critical for understanding the dynamics of the community investigated (for instance, see Sousa 1980, Breitburg 1985, Benedetti-Cecchi \& Cinelli 1994). Both individual factors of disturbance and their interaction are important for understanding patch recovery and succession (Miller 1982, Malanson 1984).

The time or season in which a gap is created by a disturbance is known to determine early successional algal assemblages because of seasonal availability of propagules of certain species (Foster 1975, Paine 1977, Emerson \& Zedler 1978, Hawkins 1981, Breitburg 1985, Kennelly 1987). Such initial variability may influence subsequent colonization, so that the gaps created in different seasons become dominated by different organisms in later successional stages (Turner 1983b, Jara \& Moreno 1984). However, other studies have modified the above theory, and indicated that the effect of season of disturbance on producing an initial colonization pattern became less evident as succession proceeded and the patches were eventually dominated by the same perennial species (Sousa 1979a, 1985, Hawkins 1981.). More information from habitats at different tidal heights and with different algal assemblages are required for generalization.

The objective of this paper is to demonstrate the effects of size and season of experimentally cleared gaps on algal recolonization and within-patch dynamics in a high intertidal, Mazzaella-Fucus-Pelvetiopsisdominated community. The study was designed to address the following questions: (1) Is the rate of algal 
recovery faster in a smaller patch (gap)? A comparison with 2 recent studies (Farrell 1989, Benedetti-Cecchi \& Cinelli 1994) using similar sizes and shape of clearings is made. (2) Do different clearing seasons affect the dominance of a particular species in this community? The 2 contrasting views on the effect of timing of disturbance on patch structure described earlier are tested. (3) What species move in when a gap of a certain size is created in a certain time of year? Predictions about community structure following various combinations of the 2 aspects of disturbance may be possible to some degree when the responses of each component species are known using the interaction term of size and season of disturbance. (4) Are limpets more abundant in small patches than in large patches? Do barnacles settle faster in large patches than in small ones? The answers to these questions test some of the hypotheses described earlier.

\section{METHODS}

Study site and community. The study area was the rocky upper intertidal zone at Prasiola Point located in Barkley Sound on the west coast of Vancouver Island, British Columbia, Canada $\left(48^{\circ} 49^{\prime} \mathrm{N}, 125^{\circ} 10^{\prime} \mathrm{W}\right)$. The area is exposed to intermediate waves from the northwest and stronger waves from the west. The experimental plots were located on rocky substratum with a gentle slope; the zone ranged from 3.4 to $4.2 \mathrm{~m}$ above Lowest Normal Tide (LNT: Canadian Chart Datum).

The algal community is dominated by 3 perennial macrophytes: Mazzaella cornucopiae (Post. \& Rupr.) Hommersand (Gigartinales, Rhodophyta; previously known as the genus Iridaea), Fucus distichus L., and Pelvetiopsis limitata Gard. (both Fucales, Phaeophyta). These species grow both in well-mixed and monospecific stands depending on wave-exposure. Other stands of $M$. cornucopiae occur in extremely waveexposed sites characterized by the alga Lessoniopsis littoralis (Tilden) Reinke and the invertebrate Pollicipes polymerus Sowerby. Fucoid stands are also found in relatively more wave-sheltered sites. Nonetheless, sites for all experimental plots were set up in areas where mixed stands of the 3 macroalgae predominate. Most $M$. cornucopiae is 2 to $3.5 \mathrm{~cm}$ in length and grows as a dense turf on the rocky substratum The 2 morphologically similar fucoids are erect and usually 4 to $7 \mathrm{~cm}$ in length at maturity. There are some ephemeral algae in the community, such as Cladophora columbiana Coll., Enteromorpha spp., Mastocarpus papillatus (Stackhouse in Withering) Guiry, Porphyra spp., Scytosiphon dotyi Wynne, benthic diatoms, Endocladia muricata (Post. \& Rupr.) J Ag., Analipus japonicus (Harvey) Wynne, Urospora sp., and also some crustose algae (Petrocelis sp., Hildenbrandia sp. and Ralfsia sp.).

Barnacles are abundant in the habitat. The dominant species is Balanus glandula Darwin, whereas B. cariosus Pallas and Chthamalus dalli Pilsbury occur less frequently. One of the major herbivores in the community are limpets, primarily Lottia digitalis Rathke and a few L. pelta Rathke. Mussels, primarily Mytilus edulis L., occur infrequently.

Experimental design. The experimental units consisted of square plots of 3 different sizes $(5 \times 5,10 \times 10$ and $20 \times 20 \mathrm{~cm})$. To test for seasonal effects, small $(5 \times$ $5 \mathrm{~cm})$ and medium $(10 \times 10 \mathrm{~cm})$ plots were cleared 4 times a year: summer (August 1991), fall (October 1991), winter (February 1992) and spring (April 1992); large plots $(20 \times 20 \mathrm{~cm})$ were cleared only in July 1991 . A.t the beginning of the experiment, a permanent transect line was placed along the shore and the position of the line was marked by hammering concrete nails or drilling bolts at every meter. The transect was placed only on mixed stands of the 3 species of interest, so that the line was sometimes disconnected due to heterogeneity in algal assemblages on the rock substratum. Using $10 \mathrm{~cm}$ intervals along the transect line, we numbered all potential small and medium plots for clearing on both sides of the transect line. Four large plots $(20 x$ $20 \mathrm{~cm}$ ) were cleared away from the transect line but within the same tidal zone. During each clearing season, 15 plots each of small and medium size were chosen using a random number table. When selecting plots for clearing, we intentionally skipped some random numbers to avoid clearing a plot adjacent to a previously cleared one; thus, at least one uncleared plot existed between cleared ones. We assume that this method enabled us to treat data as though they were unaffected by those from adjacent clearings. Four unmanipulated permanent $20 \times 20 \mathrm{~cm}$ plots were also marked in order to monitor natural seasonal fluctuations of algal abundance.

Plots were cleared by hand chiseling (for the small and medium plots) or by using a compressed-air powered drill with a chisel bit (for the large plots). This allowed us to remove all organisms (including holdfasts, barnacles, crustose algae, etc.) in the plots. The denuded plots were rechecked the next day to remove any organisms that remained. In this way, completely new substrata were in every clearing. This type of clearing resembles the major naturally occurring disturbance observed in this habitat, with the loss of cracked rock surface usually caused by sudden temperature change from winter to spring (Kim pers. obs.).

Recolonization by macroalgae was monitored every 2 mo for 2 yr. Quadrats of the same size as the experimental plots, with $1 \times 1 \mathrm{~cm}$ subplots marked off within the quadrat frame $(25,100$ and 400 subplots for small, 
medium and large quadrats, respectively), were used for measuring the abundance of organisms. Percentage cover of each species was estimated by counting the number of subplots in which a species accupied $>50 \%$ of its area; in this way, the subplots with $<50 \%$ were dropped to compensate for overestimation. The accuracy and repeatability of this technique has been tested by Dethier et al. (1993) and they reported that this method is generally more accurate than the random-point-quadrat method. Algal cover included only those thalli whose holdfasts were in the plot. Crustose algae could not be identified in the field. Therefore, we treated them as a single entity.

Densities of barnacles and limpets were monitored at every sampling date. Barnacles became too numerous to count in the medium and large plots so subunits were censused. Five and 20 randomly chosen $2 \times 2 \mathrm{~cm}$ areas were consused in each medium and large plot, respectively. Data from 4, 10 and 16 mo after initiation of summer-cleared plots are presented to compare the distribution of the invertebrates in 3 different patch sizes.

Data analysis. Percentage cover of algal species from the same plot was measured repeatedly on successive sampling dates and these values were thus correlated over time (dependent variables). Therefore, data were analyzed using a repeated measures analysis of variance (RM-ANOVA). Not all statisticians apparently agree that a repeated measures ANOVA solves a possible problem of non-independence of replicates over time; thus these results should be accepted with caution. However, the statisticians we consulted agreed with us that this method is appropriate. A 3-way (Size $\times$ Season $\times$ Time) ANOVA with repeated measures on the Time factor was separately applied for each of the 3 dominant algae and a single additional group consisting of ephemeral algae. Data from large plots $(20 \times$ $20 \mathrm{~cm}$ ) were not included in the ANOVA because they were cleared in only 1 season. Therefore, the effects of this latter treatment were deduced by inspection of graphical data. The repeated measures of percentage cover for each species did not exhibit homogeneity of variance for all pairs of measurements within subjects ('compound symmetry'; Gurevitch \& Chester 1986, Myers \& Well 1991). This precludes use of a standard univariate RM-ANOVA to analyze the withinsubject hypotheses due to inflation of type I error rates (Myers \& Well 1991). In these cases, we presented both the probability values of Huynh-Feldt adjusted degrees of freedom as well as the results of multivariate analysis of variance (MANOVA) where the assumption of sphericity was not required (Mead 1988, Myers \& Well 1991)

Cochran's $C$-test and the $F_{\text {max }}$-test (Winer 1971) were used to check homogeneity of variance. In most cases, except for total algal cover data, this assumption was violated and therefore appropriate transformations were used (Underwood 1981). Percentage cover of each algal species was arcsine-transformed prior to analysis. Barnacle and limpet densities were respectively log-and $(n+1)$ square root-transformed. Transformation did not reduce the heterogeneity to nonsignificant levels in a few cases; for example, some data from the initial sample dates. Although these data were dropped from the repeated measures ANOVA's, this procedure did not affect statistical results. Plots of residuals against estimated values were visually examined after each ANOVA to check if error terms were normally distributed. The only exceptions were the barnacle and limpet data from large plots, due to small $(n=4)$ sample size. All data were analyzed using SYSTAT version 5.2.1 for Macintosh (Wilkinson et al. 1992).

\section{RESULTS}

\section{Ūnmanipuiaied piôts}

Mazzaella cornucopiae and Fucus distichus were the most conspicuous species in unmanipulated plots during the study (mean cover 30.2 and $25.2 \%$, respectively; Fig. 1). Pelvetiopsis limitata $(11.8 \%)$ was relatively abundant in the first year, but was lower (e.g. April and June 1993) in the second year. Ephemeral algae covered only $4.4 \%$ of the plots during the experimental period. The abundance of most algae in unmanipulated plots showed a similar seasonal pattern; it was highest in February to June and was lowest in August to December. Seasonal changes in algal abundance were greater in both fucoids and ephemeral species than in M. cornucopiae (Fig. 1). Peaks in recruitment of both fucoids were observed in October of 1991, 1992 and 1993 except for P. limitata in October 1992. The timing of maximal recruitment was in contrast to the peaks in percentage covers of both species, the latter occurring in April.

\section{Size effects of disturbance}

Total algal cover following summer clearing of each of the 3 plot sizes is shown in Fig. 2. The $10 \times 10 \mathrm{~cm}$ plots had a significantly greater percentage cover of total algae than the $5 \times 5 \mathrm{~cm}$ plots. This pattern also occurred in other plots cleared in different seasons, except for those cleared in fall (Table 1). The pattern was also consistent (no significant interaction between Time and Size) throughout the entire experimental period except for in winter-cleared plots (Table 1). Col- 

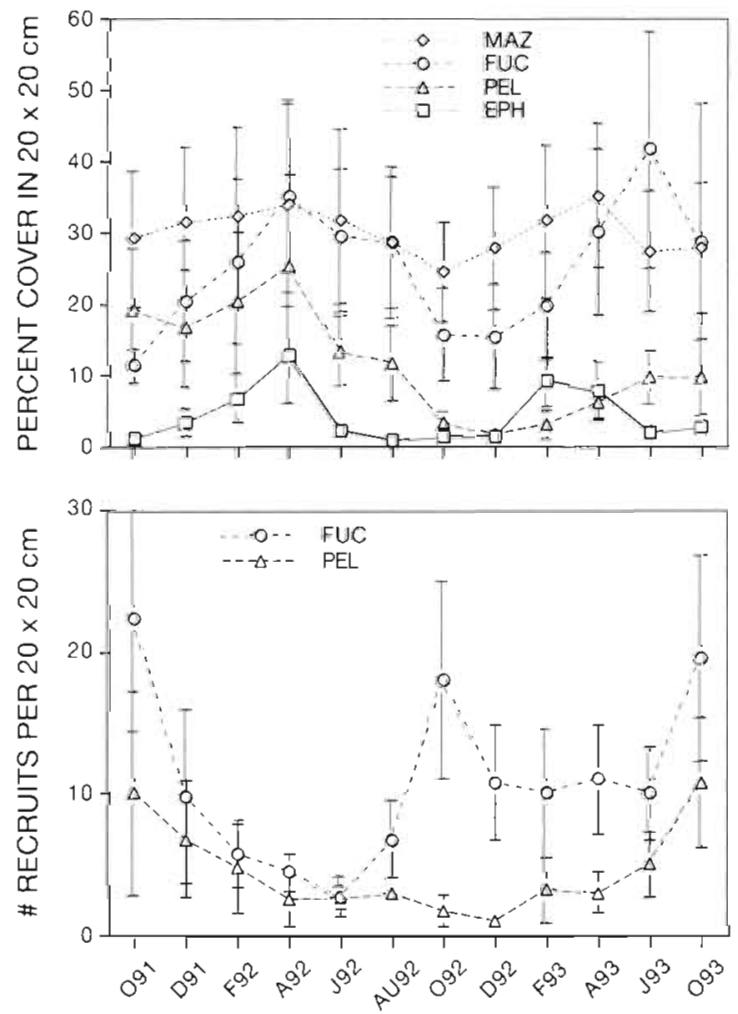

Fig, 1. Seasonal changes of algal percentage cover and the number of fucoid recruits in unmanipulated plots $(20 \times 20 \mathrm{~cm})$ at Prasiola Point, British Columbia, Canada, for 2 yr Data are the mean $\pm \mathrm{SE}$ of 4 replicates. MAZ: Mazzaella cornucopiae; FUC: Fucus distichus; PEL: Pelvetiopsis limitata; EPH: ephemeral algae

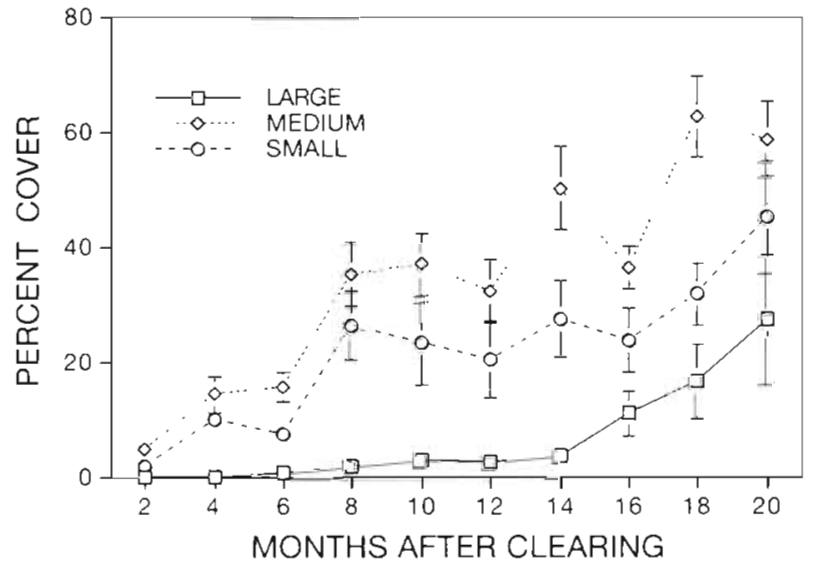

Fig. 2. Recolonization of total algae in 3 different sizes of clearing. Large clearings: $20 \times 20 \mathrm{~cm}$; medium clearings: $10 \times$ $10 \mathrm{~cm}$; small clearings: $5 \times 5 \mathrm{~cm}$. Plots cleared in the summer (August 1991) were only compared for the size effect on patch recovery. Data are the mean \pm SE of 15 replicates for small and medium plots and of 4 replicates for large plots

onization in the $20 \times 20 \mathrm{~cm}$ plots was slowest among the 3 sizes cleared in summer. Total algal cover in large plots remained less than $5 \%$ until 14 mo after clearing, whereas $8 \mathrm{mo}$ after clearing the total algal cover reached $26.4 \%$ in small plots and $35.5 \%$ in medium plots (Fig. 2).

Percentage cover of both Fucus distichus and ephemeral algae was greatest in medium plots (size effects: $p=0.001$ and $p=0.003$, respectively; Table 2 ,

Table 1. Effect of size of experimental clearings $(5 \times 5$ and $10 \times 10 \mathrm{~cm})$ on total algal cover. A separate repeated measures ANOVA was applied on data from each season; $" \mathrm{p}<0.05, \cdots p<0.01, \cdots p<0.001$ (ANOVA F). Large plots $(20 \times 20 \mathrm{~cm}$ ) were not included in analysis, as discussed in text. Univariate within subjects $F$ and probability values were adjusted using the Huynh-Feldt estimator (epsilon $=0.5134,0.4716,0.6971,0.5752$ for spring, summer, fall, winter, respectively). SYSTAT (Wilkinson et al. 1992) provides automatically adjusted $F$-values and the probabilities in the case of nonsphericity. WL: Wilks' lambda

\begin{tabular}{|c|c|c|c|c|c|c|}
\hline Source of variation & $\mathrm{df}$ & Statistic & Spring $^{\mathrm{d}}$ & Summer & Fall & Winter \\
\hline \multicolumn{7}{|l|}{ Between subject } \\
\hline Size & 1 & $\begin{array}{l}\mathrm{MS} \\
F\end{array}$ & $\begin{array}{r}5872.2 \\
4.58\end{array}$ & $\begin{array}{l}7125.6 \\
4.98\end{array}$ & $\begin{array}{r}2782.4 \\
1.81\end{array}$ & $\begin{array}{l}7191.0 \\
6.32\end{array}$ \\
\hline Error & 28 & MS & 1281.0 & 1431.8 & 1537.2 & 1138.2 \\
\hline \multicolumn{7}{|l|}{ Within subject } \\
\hline Time & 7 & $\begin{array}{l}\text { MS } \\
F\end{array}$ & $\begin{array}{l}4112.2 \\
29.18 \cdots\end{array}$ & $\begin{array}{r}3565.1 \\
14.24 \cdots\end{array}$ & $\begin{array}{l}2685.7 \\
13.24 \cdots\end{array}$ & $\begin{array}{l}3116.7 \\
18.41 \cdots\end{array}$ \\
\hline Time $\times$ Size & 7 & $\begin{array}{l}\text { MS } \\
F\end{array}$ & $\begin{array}{r}246.7 \\
1.75\end{array}$ & $\begin{array}{l}211.1 \\
0.84\end{array}$ & $\begin{array}{r}405.4 \\
1.20\end{array}$ & $\begin{array}{l}560.2 \\
3.31\end{array}$ \\
\hline Error & 196 & MS & 140.9 & 250.3 & 202.8 & 169.3 \\
\hline \multicolumn{7}{|c|}{$\begin{array}{l}\text { Multivariate repeated measures analysis } \\
\text { Effect }\end{array}$} \\
\hline Time & & $\begin{array}{l}W L \\
F\end{array}$ & $\begin{array}{c}0.191 \\
12.08 \cdots\end{array}$ & $\begin{array}{c}0.166 \\
15.80^{\cdots}\end{array}$ & $\begin{array}{l}0.385 \\
5.03 \cdots\end{array}$ & $\begin{array}{l}0.31 \\
6.98 \cdots\end{array}$ \\
\hline Time $\times$ Size & & $\begin{array}{l}\text { WL } \\
F\end{array}$ & $\begin{array}{l}0.599 \\
1.91\end{array}$ & $\begin{array}{l}0.643 \\
1.75\end{array}$ & $\begin{array}{l}0.624 \\
1.90\end{array}$ & $\begin{array}{l}0.57 \\
2.37\end{array}$ \\
\hline
\end{tabular}




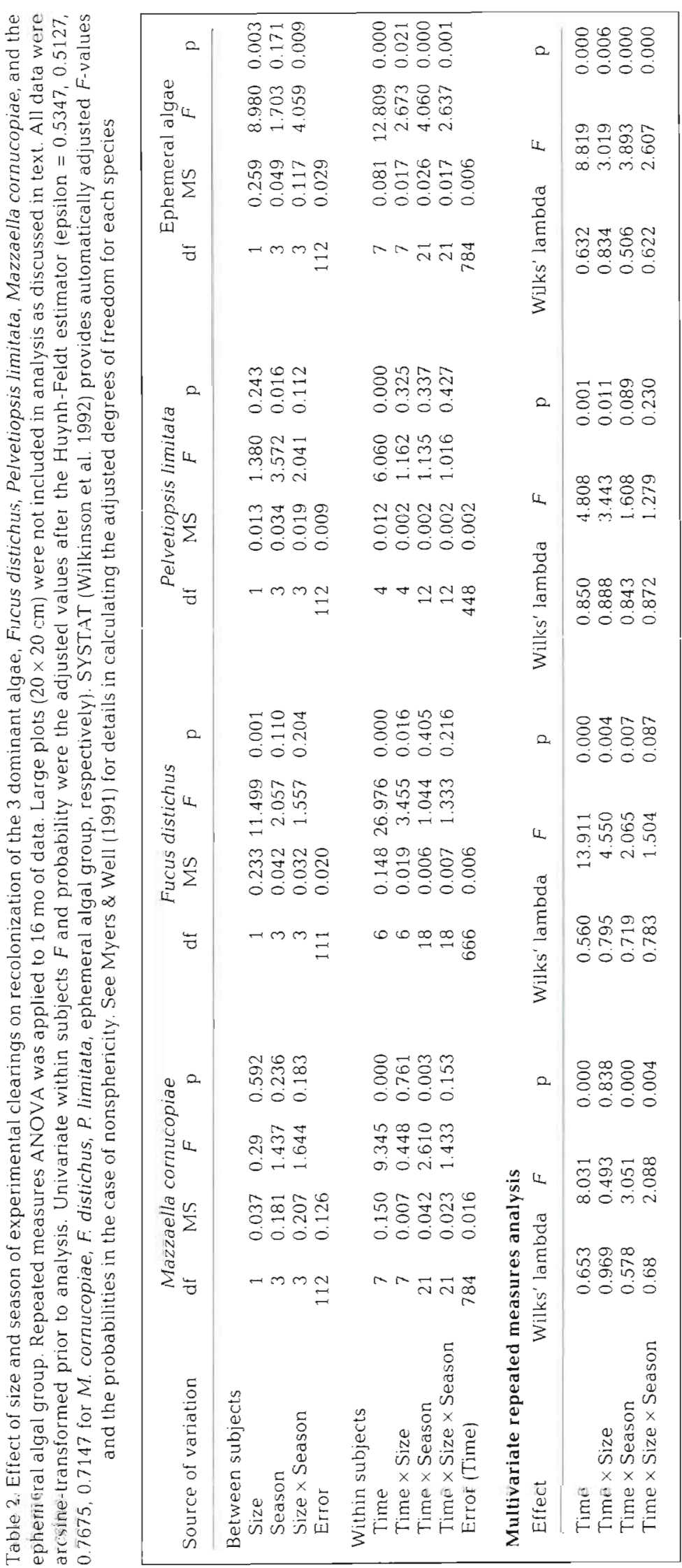

Fig. 3). However, for Mazzaella comucopiae and Pelvetiopsis limitata, differences in percentage cover between small and medium plots were not great $(p=0.592$ and $p=0.204$, respectively). Although no statistic was applied, it is obvious that percentage cover of M. cornucopiae in small and medium plots was much greater than in large plots (Fig. 3). This alga never successfully settled in large plots. Colonization by $F$. distichus occurred more rapidly in medium plots than in small and large plots (which it colonized at similar rates), although this pattern was not recognizable during the first 6 mo (Fig. 3). However, ephemeral algae colonized rapidly from early in the succession, especially in the medium plots. Ephemeral species in medium and small plots consisted of a similar assemblage. In medium piots, crustose algae and Cladophora columbiana, Scytosiphon dotyi and Endocladia muricata were most abundant (in decreasing abundance). Small plots were setiled by crustosc algae and by $S$ dotyi, $C$, columbiana and Polysiphonia sp. In contrast, the ephemeral group in large plots was dominated by Porphyra sp., followed by E. muricata and $S$. dotyi. We occasionally found a few small clumps of $M$. cornucopiae, especially in spring, but these usually disappeared by the next sampling dates. $P$ limitata was the species least affected by the size of the disturbance; it showed similar cover in all 3 plot sizes over time.

\section{Seasonal effects of disturbance}

In medium and small plots, there was no difference in algal abundance among plots cleared in different seasons, except for Pelvetiopsis limitata $(p=0.02$, Table 2 ; analysis includes data over $16 \mathrm{~mol}$. The mean percentage cover of $P$. limitata over the duration of the experiment from the summer clearing averaged over the 2 patch sizes was $2.5 \%$. This is significantly greater than those from the winter $(0.7 \%)$ and the fall clearings $(0.5 \%)$ (Tukey's HSD: $p=0.049$ and $p=0.022$, respectively). Fucus distichus had a high percentage cover in summer-cleared medium plots (Fig. 5). In small plots, Mazzaella cornucopiae showed relatively faster colonization in summer- and fall-cleared plots than in spring-and winter-cleared plots (Fig. 4). 


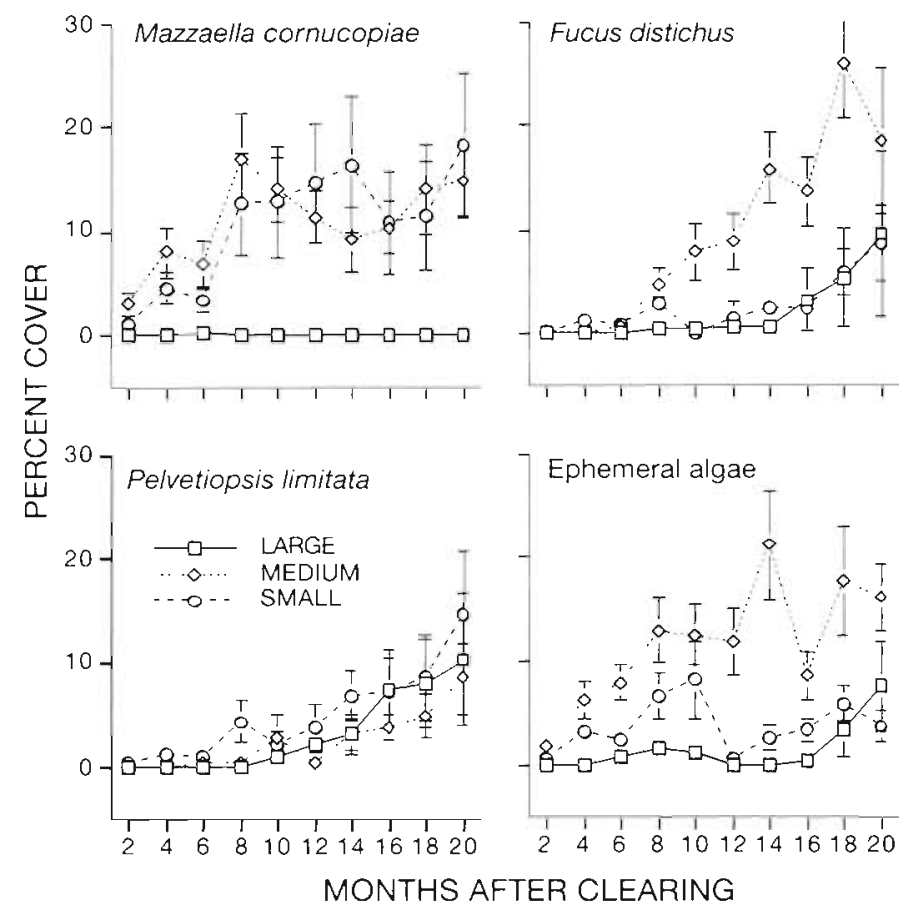

Fig. 3. Patch recovery of each dominant alga, Mazzaella cornucopiae, Fucus distichus, Pelvetiopsis limitata, and ephemeral algae, in 3 different sizes of clearing. Data shown are from the summercleared (August 1991) plots. Data are the mean \pm SE of 15 replicates for small and medium plots and of 4 replicates for large plots

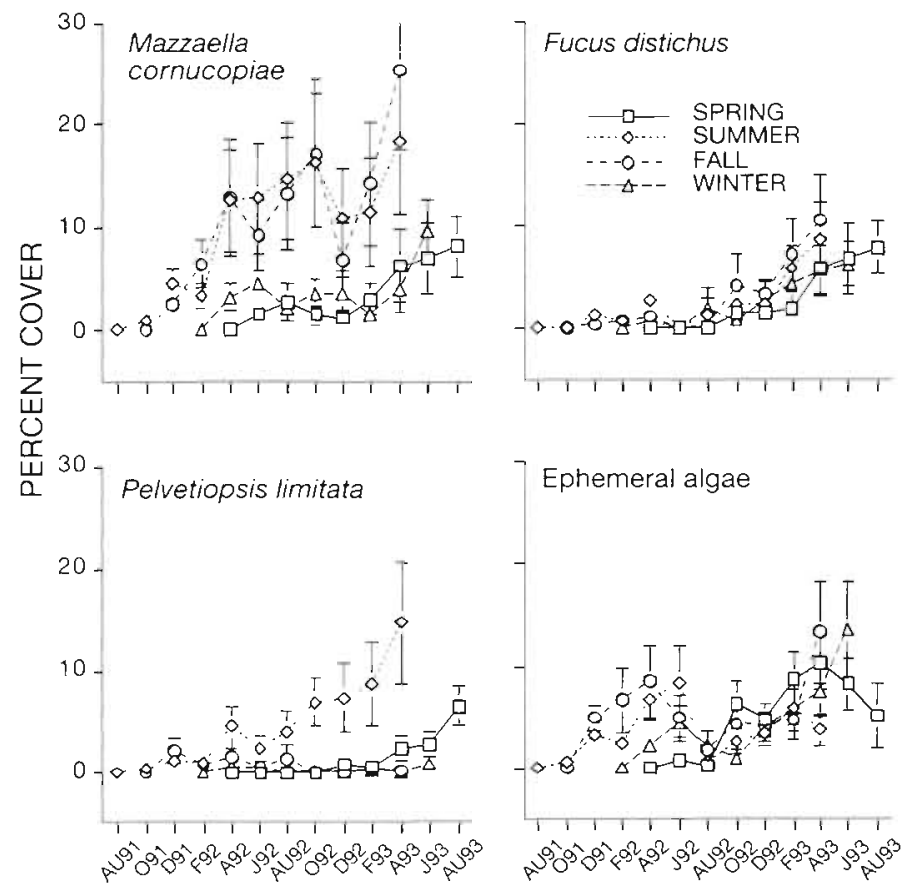

Fig. 4. Effect of season of clearing on algal recovery of each species in small plots $(5 \times 5 \mathrm{~cm})$. The time for each seasonal clearing is August 1991 (for summer), October 1991 (for fall), February 1992 (for winter) and April 1992 (for spring). Data are the mean \pm SE of 15 replicates

\section{Interactions of the disturbance factors}

For percentage cover of ephemeral algae there was a significant interaction between size of plot and season of clearing ( $p=0.009$; Table 2$)$. The greater abundance of ephemeral algae in medium plots was found only in spring- and summer-cleared plots, whereas a similar abundance of these algae occurred in the medium and small plots cleared in fall and winter (Figs. 4 \& 5). This difference, however, was not consistent during the successional period (Time $\times$ Size $\times$ Season interaction: $p=0.001$ ); the largest difference occurred only in October 1992 (Figs. 4 \& 5).

Responses of algae to the different sizes and seasons of disturbance were quite variable. For example, relatively high cover and rapid colonization of Mazzaella cornucopiae were found in summer and fall clearings of the small plots. In contrast, the rate of colonization of this alga was slower in medium fall-cleared plots (Figs. 4 \& 5).

When time is taken into account, additional variation occurs in the interpretation of the effect of size of clearing on Fucus distichus colonization. The pattern of $F$ distichus abundance (medium plots > small plots) was not consistent during the experiment (Time $\times$ Size in MANOVA; $p=0.004$; the probability value in the MANOVA was used when the nonsphericity within subjects was severe); for example, the size effect was significant only in summer plots 10 mo after clearing (Fig. 3).

In contrast, the seasonal effect on Pelvetiopsis limitata abundance (summer > winter, fall clearings) was similar between medium and small plots (Size $\times$ Season interaction: $p=0.112$ ) and also was consistent over successional time (Time $\times$ Season interaction: $\mathrm{p}=0.337$; Table 2, Figs. $4 \& 5$ ).

\section{Barnacle and limpet densities}

There were significant differences in barnacle density in the 3 patch sizes 4,10, and 16 mo after clearing (ANOVA: $F_{2,31}=4.088,53.708,19.361$; $\mathrm{p}<0.05, \mathrm{p}<0.0001, \mathrm{p}<0.0001$, respectively; Fig. 6). Tukey's HSD tests indicate that barnacle densities in the small patches were significantly lower than in either the medium or large patches on all tested dates (Fig. 6). Differences between medium and large patches were not significant for the first 2 sample dates. However, mean density in medium patches was higher than in large patches 16 mo after initiation. 

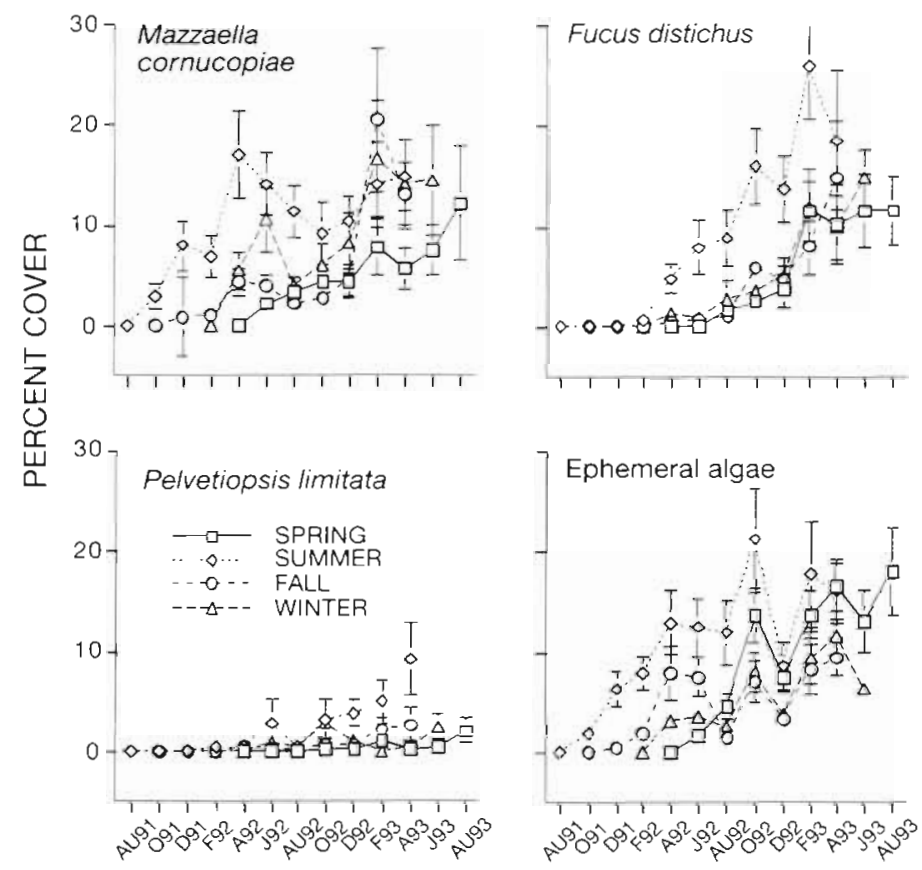

Fig. 5. Effect of season of clearing on algal recovery of each species is medium plots $(10 \times 10 \mathrm{~cm})$. See Fig. 4 for captions and number of replicates

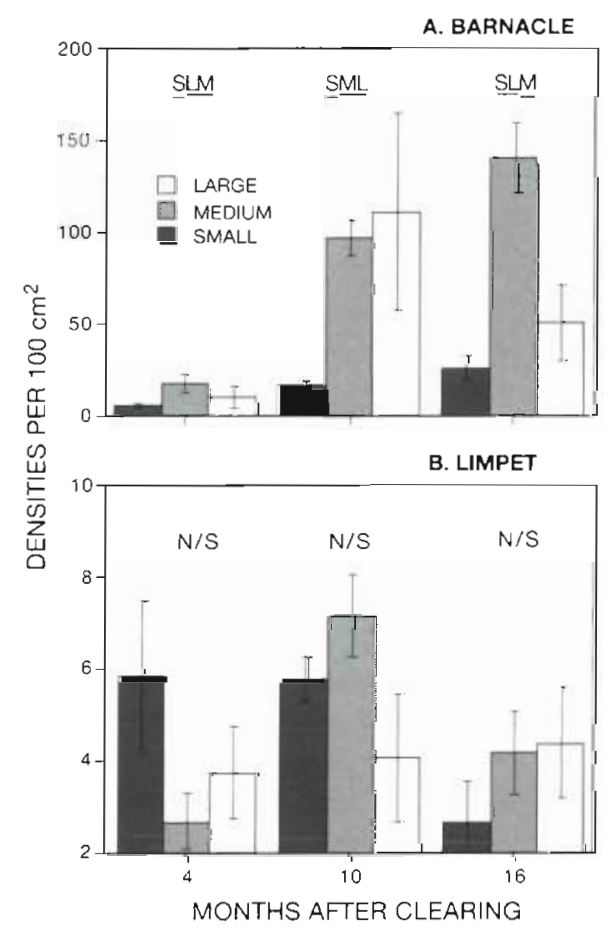

Fig. 6. (A) Barnacle and (B) limpet densities in the 3 sizes of patch at 3 sampling dates (4, 10, 16 mo after clearing). Data are the mean \pm SE of 15 replicates for small and medium plots and of 4 replicates for large plots. When results of ANOVA on 3 sizes were significant, results of Tukey's HSD tests were labeled (e.g. S LM indicates that density in small patch is significantly different from than that of either large or medium patch). N/S: $p>0.05$
Limpet densities were not significantly different between patch sizes for any sampling date ( $p>0.1$, in all cases; ANOVA was used on each sample date). Although the relative abundance of limpets at Month 4 was higher in small patches $\left(5.9\right.$ per $\left.100 \mathrm{~cm}^{2}\right)$ than in medium patches $\left(2.7\right.$ per $100 \mathrm{~cm}^{2}$ ), the mean densities averaged over all 3 sample dates were similar for all patch sizes $\left(4.8,4.7,4.1\right.$ per $100 \mathrm{~cm}^{2}$ in small, medium and large, respectively)

\section{DISCUSSION}

\section{Size effects of disturbance}

In this study the rate of patch colonization was affected by the size of disturbance. The medium $(10 \times 10 \mathrm{~cm})$ patches were colonized fastesi, followed by the small $(5 \times 5 \mathrm{~cm})$ and large $(20 \times$ $20 \mathrm{~cm}$ ) patches. The present results are different from those of previous studies by Farrell (1989) and Benedetti-Cecchi \& Cinelii (1994), and indicate that negative factors inhibited patch colonization of both small and large plots.

In small plots, adult plants surrounding the small patches tend to shade out and/or whiplash the cleared space, decreasing the attachment and growth of propagules of their own or other species (Dayton 1975, Sousa 1979a, Velimirov \& Griffths 1979, Reed \& Foster 1984, Kennelly 1989). These competitive interactions among the species recently settled in a patch and the organisms surrounding that patch have been emphasized as mechanisms limiting colonization of small gaps (Connell \& Keough 1985, Sousa 1985). Fucus distichus and Pelvetiopsis limitata are the most likely species to shade or whiplash the cleared space in small plots. Since the fucoids are 4 to $7 \mathrm{~cm}$ in length, it is possible for those growing adjacent to the patch to completely cover the $5 \times 5 \mathrm{~cm}$ plots at low tides; this was commonly observed in the field. The whiplashing of fucoids at high tides may deleteriously affect the settlement of barnacles and their own recruitment in this habitat. Our results negate the hypothesis that smaller patches are colonized more rapidly, as proposed by Sousa (1985) and Farrell (1989). The above deterrent factor(s) appear(s) to be more important in patch recovery of the $5 \times 5 \mathrm{~cm}$ plots in this community than a potential benefit of the greater edge ratio. Sousa (1984a) reported that slow colonization in small patches was caused by increased herbivore density (i.e. limpets). Our data provided no evidence for more intensive herbivory in the small plots. Limpet abundance was statistically similar among the 3 patch sizes 
Algal recovery in the large patches was not completely inhibited, but only delayed in comparison with colonization of small and medium patches. Whatever the mechanism(s) accounting for the delay in colonization in large plots, its (their) effect was strong in the first year, but generally decreased as succession proceeded. The slow (or delayed) colonization in the large patches may be explained by the following factors: (1) relatively stronger heat stress and desiccation in the center area of large patches which may cause higher mortality of settling algae, (2) short dispersal distance of component species (e.g. fucoids) and poor colonization of the vegetatively propagating turf red alga Mazzaella cornucopiae, or (3) simply the lower ratio of edge to area. A similar pattern has been documented in the high intertidal on the Oregon coast of the USA (Farrell 1989). Farrell (1989) claimed that low recruitment or high mortality of algae in the gap $(16 \times 16 \mathrm{~cm})$ interior was due to heat stress and desiccation and short dispersal distance of Fucus distichus and Pelvetiopsis limitata. Based on the sizes of component species in this community, it is clear that much of the area in the $20 \times 20 \mathrm{~cm}$ plots is directly exposed to sunlight. Consequently, zygotes and embryos of fucoids may undergo higher mortality due to severe cellular dehydration (Davison et al. 1993). Although no numeric data are available on the dispersal distance of $F$ distichus and $P$. limitata, this distance is thought to be 'very short' (Sousa 1984a, Hoffman 1987, Farrell 1989, Menge et al. 1993).

The intensity of the factors limiting colonization in our 2 extreme patch sizes may decrease as patch size approaches an intermediate size. Medium patches may simply receive the advantages of the reduction of the negative factors of the 2 size extremes. Similarly, the intermediate disturbance hypothesis (Horn 1975, Connell 1978) suggests that an intermediate frequency of disturbance may allow the coexistence of species with different life history strategies, which in turn allows for the highest species diversity. Furthermore, Miller (1982) claimed that size of disturbance provides an extension of the intermediate disturbance hypothesis. He explained that patches of intermediate size may allow equal colonization of both the 'competitive species', which cover a disturbed area by dispersing or growing primarily from around the patch perimeter, and the 'colonizing species', which colonize rapidly through high growth and/or dispersal rate. In this community the 3 dominant algae may not functionally fit into these 2 groups of species. However, medium patches in this study were generally recolonized by a relatively well-mixed combination of all groups including Mazzaella cornucopiae (rare in large patches) and Fucus distichus (low in small patches). Yet, it is still difficult to generalize the effect of patch size on the rate of colonization because the rate may vary with habitat and algal assemblage. For example, in Farrell's (1989) study, although the size of clearings at a given tidal height was similar to that of this study (e.g. $4 \times 4$, $8 \times 8$ and $16 \times 16 \mathrm{~cm}$ ), he found that the effect of surrounding plants, which was a negative one in small patches of our study, was positive in its effect on the settlement of other or their own species. Furthermore, M. cornucopiae was absent in his study areas, but Endocladia muricata, which is rare in our site, was abundant and colonized in the large patches. In Benedetti-Cecchi \& Cinelli's (1994) study, the 3 sizes of clearing were the same as in our study, but the tidal height and algal assemblage were different. Benedetti-Cecchi \& Cinelli (1994) found that most algal species (i.e. Corallina, Polysiphonia) colonized by the settlement of propagules (i.e. zygotes), making vegetative propagation unimportant.

Our result is the first report which experimentally supports Miller's (1982) hypothesis with regard to intertidal habitats and calls for replicate studies in other habitats.

\section{Effect of timing of disturbance}

The differences in algal abundance among patches of similar age but produced at different seasons were species-specific. Algal species responded differently to the seasonal effect of disturbance depending on their life histories and reproductive strategies. First of all, Fucus distichus and Pelvetiopsis limitata, which are characterized as being slow-growing, perennial, and dispersed by propagules, tended to dominate patches created 'just before' (e.g. 2 mo) their recruitment peaks, compared to patches made at other times. As a result, summer clearings (August 1991) created 2 mo before the recruitment peak of fucoids (October 1991; Fig. 1) gave rise to greater cover of P. limitata in both small and medium plots than did plots cleared in any other season. F. distichus showed a similar pattern but only in the medium patches. New substrata created 'just before' the peak of reproduction may receive greater numbers of fucoid propagules with no interference from previously settled species. For these species the time of gap creation was important because the initial recruitment determined the later succession, as also shown in other studies (Turner 1983b, Jara \& Moreno 1984). Jara \& Moreno (1984) reported that plots cleared in spring were dominated by ephemeral algae but, if cleared in fall, plots were filled by barnacles. These results were due to seasonal availability of spores and inhibition among settled organisms and later species. Recently, Benedetti-Cecchi \& Cinelli (1994) reported examples 
of significant seasonal effects on recovery of patches. These patterns, however, varied with algal species and site.

On the other hand, for species such as Mazzaella cornucopiae which propagate vegetatively (Olson 1985), the timing of clearing generally did not influence dominance of this alga in the plots. However, in medium patches the abundance of $M$. cornucopiae in wintercleared patches (made 2 mo before the abundance peak) was slightly greater than in the other patches cleared in different seasons.

In this study seasonal effects of disturbance were highly species-specific; season-of-clearing had more effect on species dispersing by propagules and less on species reproducing by vegetative ingrowth. Also, this study supports the generalization that the abundance of a species is most enhanced by disturbance if a patch is created when the propagules of the species are available for settlement (Denley \& Underwood 1979 , Sousa 1979a, Hawkins 1981, Breitburg 1985, Kennelly 1987).

\section{Responses of barnacles and limpets to the size of disturbance}

The abundance of recolonizing barnacles was influenced by patch size, and this may be due to the deleterious effects of the algal canopy. Several authors have found that algal cover reduces barnacle settlement, or decreases their survival, by scouring young barnacles (Woodin \& Jackson 1979, Hawkins 1983) or overgrowing their apertures (Dayton 1974, Farrell 1991). In contrast, it has been reported that barnacles are more abundant under algal canopies due to a decrease in desiccation-caused mortality (Dayton 1971, Farrell 1989). In this study the negative effects of macroalgae on barnacles appeared to be more important in controlling barnacle densities in the small patches. Both. fucoids ( 4 to $7 \mathrm{~cm}$ in size) seemed 'large' enough to 'whiplash' young barnacles in the $5 \times 5 \mathrm{~cm}$ plots. Mazzaella cornucopiae sometimes appeared to kill barnacles by overgrowing them.

Limpet abundance during succession was not influenced by clearing size; mean densities were similar in all patch sizes. Thus, the relationship between limpet grazing and algal colonization as related to patch size in this study does not support the results obtained from other studies. Some studies have found that limpet densities decrease with increasing patch size. Suchanek (1978) and Sousa (1984a) conducted experiments in mussel beds and Farrell's (1989) study was done in an upper intertidal zone. Both studies revealed that limpets tend to aggregate at patch edges. Small plots with a greater unit boundary area might attract a rela- tively greater density of limpets (Farrell 1989). Some authors have claimed that increased limpet density in small patches was responsible for slower colonization of the patch (see Sousa 1984b, 1985 for references). In this study limpet densities were highest in small patches, but only initially. Thus the density distribution of limpets among patch sizes showed high variability over time.

\section{Responses of individual algal species to disturbance}

The progression of species settlement and replacement in a disturbed patch can be predicted to some degree when disturbance is analyzed by a multidimensional model. Several models have predicted the species diversity of patches by examining several characteristics of disturbance together rather than considering each separateiy (Millier 1982, Malanson 1984). In this study patterns of succession following disturbance have been interpreted with a 2-dimensional view, incorporating the size of disturbance and the time at which inle disturbañce occurred.

What species move in when a gap of a particular size is created in a particular season? The answer to this question can now be predicted with some certainty for this community. The following 4 cases illustrate some predictions about community structure made by using the results from this study. (1) If a small gap is created in fall, the gap will be dominated only by Mazzaella cornucopiae. (2) If a small gap is formed in summer, both $M$. cornucopiae and Pelvetiopsis limitata will dominate the gap. However, the canopy-forming fucoid is expected to finally exclude the short, turf-forming red alga by shading (Kim 1995, Kim \& DeWreede unpubl.). (3) If a medium gap is made in summer, $M$. cornucopiae and ephemeral algae will dominate the space early in the succession (e.g. $<6$ mo), but later Fucus distichus will gradually colonize and become a codominant. The patch may be a mixture of the 3 algal species, and their relative proportion will fluctuate seasonally. A similar pattern of patch dynamics is expected in a medium gap created in other seasons. (4) If a large gap is created in summer, the patch will recover relatively slowly, but fucoids are expected to dominate the gap with only a seasonal appearance of ephemeral algae. $M$. cornucopiae may not appear for at least the first 3 yr after disturbance (Kim 1995).

Large patch sizes (due to natural disturbance) have been found to occur less frequently than smaller ones (Sousa 1979b, Paine \& Levin 1981, Farrell 1989). If this is the case, then in our study the population of Mazzaella cornucopiae is expected to remain as a co-dominant in this community. In a single-species-dominated community, the sequence of succession within a patch 
can be deterministic and lead to the monopolization of space within the patch by the one competitively dominant and/or long-lived species. However, for multispecies-dominated communities information is required on the competitive abilities of all the component species in order to better understand the within-patch dynamics. Thus, to predict the natural dynamics of this Mazzaella-Fucus-Pelvetiopsis-dominated community, at least 2 other factors may be significant; frequency of disturbance size and the mechanisms of interspecific interactions of the dominants (Kim \& DeWreede unpubl.).

Acknowledgements. We are grateful to P. O. Ang Jr, P. G. Harrison, A. Sussmann and R. Turkington for providing helpful comments on the earlier versions of this manuscript. Special thanks go to H. J. Eom and R. W. Schutz for critical advice on statistics. We thank the staff of Bamfield Marine Station for using the facilities and the following people for assistance in the field: A. Huang, A. Park, B. Philips, R. Scrosati, F. Shaughnessy. This study was supported by NSERC grant no. 5-89872 to R.E.D.

\section{LITERATURE CITED}

Begon M, Harper JL, Townsend CR (1990) Ecology: individuals, populations and communities, 2nd edn. Blackwell, London

Benedetti-Cecchi L, Cinelli F (1994) Recovery of patches in an assemblage of geniculate coraline algae variability at different successional stages. Mar Ecol Prog Ser 110:9-18

Breitburg DL (1985) Development of a subtidal epibenthic community: factors affecting species composition and the mechanisms of succession. Oecologia 65:173-184

Connell JH (1978) Diversity in tropical rain forests and coral reefs. Science 199:1302-1310

Connell JH, Keough MJ (1985) Disturbance and patch dynamics of subtidal marine animals on hard substrata. In: Pickett STA, White PS (eds) The ecology of natural disturbance and patch dynamics. Academic Press, Orlando, p $125-151$

Davis RM, Cantlon JE (1969) Effect of size area open to colonization on species composition in early old-field succession. Bull Torrey Bot Club 96:660-673

Davison IR, Johnson LE, Brawley SH (1993) Sublethal stress in the intertidal zone: tidal emersion inhibits photosynthesis and retards development in embryos of the brown alga Pelvetia fastigiata. Oecologia 96:483-492

Dayton PK (1971) Competition, disturbance and community organization: the provision and subsequent utilization of space in a rocky intertidal community. Ecol Monogr 41. $351-389$

Dayton PK (1974) Dispersion, dispersal and persistence of the annual intertidal alga, Postelsia palmaeformis Ruprecht. Ecology 54:433-438

Dayton PK (1975) Experimental evaluation of ecological dominance in a rocky intertidal algal community. Ecol Monogr 45:137-159

Dayton PK, Tegner MJ, Parnell PE, Edwards PB (1992) Temporal and spatial patterns of disturbance and recovery in a kelp forest community. Ecol Monogr 62:421-445
Denley EJ, Underwood AJ (1979) Experiments on factors influencing settlement, survivorship and growth of two species of barnacles in New South Wales. J exp mar Biol Ecol 36:269-293

Dethier MN, Graham ES, Cohen S, Tear LM (1993) Visual versus random-point percent cover estimation: 'objective' is not always better. Mar Ecol Prog Ser 96:93-100

Dungan ML (1986) Three-way interactions: barnacles, limpets and algae in a Sonoran Desert rocky intertidal zone. Am Nat 127:292-316

Dye AH (1993) Recolonization of intertidal macroalgae in relation to gap size and molluscan herbivory on a rocky shore on the east coast of southern Africa. Mar Ecol Prog Ser 95:263-271

Emerson SE, Zedler JB (1978) Recolonization of intertidal algae: an experimental study. Mar Biol 44:315-324

Farrell TM (1989) Succession in a rocky intertidal community: the importance of disturbance size and position within a disturbed patch. J exp mar Biol Ecol 128:57-78

Farrell TM (1991) Models and mechanisms of succession: an example from a rocky intertidal community. Ecol Monogr $61: 95-113$

Foster MS (1975) Algal succession in a Macrocystis pyrifera forest. Mar Biol 32:313-329

Gurevitch J, Chester JST (1986) Analysis of repeated measures experiments. Ecology 67:251-255

Hawkins SJ (1981) The influence of season and barnacles on the algal colonization of Patella vulgata exclusion areas. $\mathrm{J}$ mar biol Ass UK 61:1-15

Hawkins SJ (1983) Interactions of Patella and macroalgae with settling Semibalanus balanoides (L.\}. J exp mar Biol Ecol 71:55-72

Hoffmann AJ (1987) The arrival of seaweed propagules at the shore: a review. Botanica Mar 30:151-165

Horn HS (1975) Markovian processes of forest succession. In: Cody ML, Diamond JM (eds) Ecology and evolution of communities. Harvard University Press, Cambridge, p $196-211$

Jara HF, Moreno CA (1984) Herbivory and structure in a midlittoral rocky community: a case in southern Chile. Ecology 65:28-38

Kennelly SJ (1987) Physical disturbances in an Australian kelp community. I. Temporal effects. Mar Ecol Prog Ser 40:145-153

Kennelly SJ (1989) Effects of kelp canopies on understorey species due to shade and scour. Mar Ecol Prog Ser 50: $123-130$

Keough MJ (1984) Effects of patch size on the abundance of sessile marine invertebrates. Ecology 65:423-437

Kim JH (1995) Intertidal community structure, dynamics and models: mechanisms and the role of biotic and abiotic interactions. PhD thesis, University of British Columbia, Vancouver

Malanson GP (1984) Intensity as a third factor of disturbance regime and its effect on species diversity. Oikos 43: $411-413$

Mead R (1988) The design of experiments. Cambridge University Press, Cambridge

Menge BA, Farrell TM, Olson AM, Van Tamelen P, Turner T (1993) Algal recruitment and the maintenance of a plant mosaic in the low intertidal region on the Oregon coast. $\mathrm{J}$ exp mar Biol Ecol 170:91-116

Miller TE (1982) Community diversity and interactions between the size and frequency of disturbance. Am Nat 120:533-536

Myers JL, Well AD (1991) Research design and statıstical analysis. HarperCollins Publishers, New York 
Olson AM (1985) Early succession in beds of the red alga, Iridaea cornucopiae Post. \& Rupr. (Gigartinaceae): alternate pathways. MS thesis, Oregon State University, Corvallis

Osman RW (1977) The establishment and development of a marine epifaunal community. Ecol Monogr 47:37-63

Paine RT (1977) Controlled manipulations in the marine intertidal zone and their contributions to ecological theory. Spec Publ Acad nat Sci Philadelphia 12:245-270

Paine RT, Levin SA (1981) Intertidal landscapes: disturbance and dynamics of pattern. Ecol Monogr 51:145-178

Palumbi SR, Jackson JBC (1982) Ecology of cryptic coral reet communities. 2. Recovery from small disturbance events by encrusting bryozoa: the influence of 'host' species and lesion size. J exp mar Biol Ecol 64:103-115

Reed DC, Foster MS (1984) The effects of canopy shading on algal recruitment and growth in a giant kelp forest. Ecology 65:937-948

Sousa WP (1979a) Experimental investigations of disturbance and ecological succession in a rocky intertidal algal community. Ecol Monogr 49:227-254

Sousa WP (1979b) Disturbance in marine intertidal boulder fields: the non-equilibrium maintenance of species diversity. Ecology 60:1225-1239

Sousa WP (1980) The responses of a community to disturbance: the importance of successional age and species' life histrias Decologia 45:72-81

Sousa WP (1984a) lntertidal mosaics: patch size, propagule

This article was submitted to the editor availability, and spatially variable patterns of succession Ecology 65:1918-1935

Sousa WP (1984b) The role of disturbance in natural communities. A Rev Ecol Syst 15:353-391

Sousa WP (1985) Disturbance and patch dynamics on rocky intertidal shores. In: Pickett STA, White PS (eds) The ecology of natural disturbance and patch dynamics. Academic Press, Orlando, p 101-124

Suchanek TH (1978) The ecology of Mytilus edulus L. in exposed rocky intertidal communities. J exp mar Biol Ecol $31: 105-120$

Turner T (1983a) Complexity of early and middle successional stages in a rocky intertidal surfgrass community. Oecologia 60:56-65

Turner T (1983b) Facilitation as a successional mechanism in a rocky intertıdal community. Am Nat 121:729-738

Underwood AJ (1981) Techniques of analysis of variance in experimental marine biology and ecology. Oceanogr mar Biol A Rev 19:513-605

Velimirov B, Griffiths CL (1979) Wave-induced kelp movement and its importance for community structure. Botanica Mar 22:169-172

Wilkinson L, Hill MA, Vang E (1992i SYSTAT: statistics, version 5.2.1. SYSTAT, Evanston, IL

Winer BJ (1971) Statistical principles in experimental design, 2nd edn. McGraw-Hill, New York

Woodin SA, Jackson JBC (1979) Interphyletic competition among marine bentinos. Án Zuöi 19.1029-1043

Manuscript first received: July 14, 1995

Revised version accepted: October 12, 1995 